\title{
A Derivation of Probabilities of Correct and Wrongful Conviction in a Criminal Trial
}

Lando, Henrik

Document Version

Final published version

Publication date:

2006

License

CC BY-NC-ND

Citation for published version (APA):

Lando, H. (2006). A Derivation of Probabilities of Correct and Wrongful Conviction in a Criminal Trial.

Link to publication in CBS Research Portal

\section{General rights}

Copyright and moral rights for the publications made accessible in the public portal are retained by the authors and/or other copyright owners and it is a condition of accessing publications that users recognise and abide by the legal requirements associated with these rights.

\section{Take down policy}

If you believe that this document breaches copyright please contact us (research.lib@cbs.dk) providing details, and we will remove access to the work immediately and investigate your claim.

Download date: 26. Apr. 2023 


\title{
A Derivation of Probabilities of Correct and Wrongful Conviction in a Criminal Trial
}

\author{
Henrik Lando \\ Copenhagen Business School and Lefic
}

March 14, 2006

\begin{abstract}
This article derives key variables in the analysis of standards of proof in criminal law from basic conditional probabilities. The variables derived are the probability of correct and wrongful conviction, the expected sanction and society's incarceration costs, while the basic conditional probabilities are the probability of observing (any given) evidence against individual $i$ given that individual $j$ committed the crime (for any $j$ including $j$ equal to $i$ ). The variables are derived from the conditional probabilities as a function of the standard of the proof using simple Bayesian updating.
\end{abstract}

\section{Introduction}

In the literature that models a Court's inference concerning the guilt of a defendant in a criminal trial ${ }^{1}$, the probability of observing the evidence given that the defendant did commit the crime, and the probability of observing it given that someone other than the defendant committed it are taken as basic concepts. However, it is not clear whether these are conditional or joint probabilities, and neither is the concept of the probability of observing the evidence given that some other person than the defendant committed the crime. This article derives these (joint) probability distributions within a Bayesian framework from the conditional probability distributions, which for each person assigns the probability of observing the evidence given that the person committed the crime. Since other key variables such as the expected sanction, the expected number of wrongly convicted and the total number of convictions per crime committed (which determines society's sanctioning costs) can be derived from the two probability distributions that are conventionally treated as basic to the analysis, this article will also derive these variables from the conditional probabilities. In all, while the analysis here will not point to errors in the existing literature, but will rather establish the correctness of the analysis in e.g. Miceli $(1990,1991)$, the aim is to ground the analysis of inference in criminal law securely on Bayesian updating ${ }^{2}$.

\footnotetext{
${ }^{1}$ For an overview, see Polinsky and Shavell (2000).

${ }^{2}$ Experience shows how easy it is to make mistakes when modeling probabilistic inference. Deriving probabilities from simple Bayesian updating can eliminate the potential for error.
} 


\section{Basic Assumptions}

It will be assumed that when a crime has been committed, the identity of the offender and not the nature of act committed is in doubt; the act will be assumed to create harm which leaves essentially very little (in the model no) doubt that the crime has been committed. Assault, robbery, and certain kinds of homicide all fall into this category. The task for the Court is to infer the probability of a person's guilt based on the evidence, i.e. based on information concerning circumstances of the crime (including knowledge of the process by which this information has been provided by first the police, and then the prosecution).

\section{The Model}

Let there be $N$ potential offenders, each of whom may or may not commit a crime on a given day. Whether or not an individual commits a crime depends on his or her benefit from committing it in relation to the expected disutility of the possibility of being sanctioned. The $N$ individuals are assumed to possibly differ in the benefit they obtain from committing the crime under consideration, but ex-ante, before the evidence becomes known to the Court, they are indistinguishable from the point of view of the Court ${ }^{3}$. For simplicity, it can be assumed that a person can only commit one crime on the given day; the possibility of multiple offenses by the same person on a given day, which is realistic for e.g. theft will not be discussed here, although the analysis can be extended to cover it. Moreover, attention will for the sake of simplicity focus on the case where only one crime is committed on a given day. Naturally, the more realistic case is where many crimes are committed each day but each crime can then be analysed as will be done here, and information concerning the nature and number of other crimes committed can then be included as part of the evidence arising in any singly case, to the extent that it is relevant for excluding or including possible suspects. Implicitly, when only one crime is committed on a given day, only one individual's benefit is greater than the expected sanction (on that day). For consistency of the model, it should then be verified that the expected sanction, which depends among other factors on the standard of proof and thus on the way in which the Court infers guilt from evidence, is at a level such that one and only one person's benefit exceeds the expected sanction ${ }^{4}$. This consistency requirement is easily met (since a distribution of benefits can be assumed that meets the requirement), and the purpose of mentioning this aspect is to stress that the commission of a crime is not a stochastic event in the model. Thus, it may well be known by everybody that a crime will be committed each day; however, as long as the Court does not have any information

\footnotetext{
${ }^{3}$ The analysis can be extended to the case where individuals belong to sub-groups of society with different propensities for crime, see note? below.

${ }^{4}$ Naturally, this can be extended to $M$ criminal acts, where the equilibrium will be one where the fraction of the population whose benefit exceeds the expected sanction will commit crime.
} 
concerning the benefits of particular individuals the problem of inferring who committed the crime remains. In the absence of any information concerning individuals' types, the Court must set the prior probability that any individual committed the crime equal to $1 / N^{5}$.

The ex-ante probability of guilt will be updated by the Court on the basis of the evidence arising as a result of investigative effort. The evidence will be denoted by $e$ and will be assumed to be stochastic; for example, a witness may stochastically show up at a crucial moment. The evidence $e$ may be thought of as a collection of statements and measurements (blood tests, DNA-tests, all kinds of forensic evidence) concerning states of the world. Also, when the Court decides on the guilt of a person, it may be relevant how the information concerning the circumstances of the crime has been collected, why the police and later the prosecution chose to focus on a person as a key suspect etc., knowledge of this kind will be taken to be included in $e$.

In the section below, the probability of a person $i$ 's guilt given the evidence will be derived from the conditional probabilities of observing the evidence given that $i$ committed the crime and of observing the evidence given that some other person $j$ committed the crime. Subsequently, the probability of a correct and a wrongful conviction will be derived (as a function of the standard of proof) from these same conditional probabilities.

As mentioned, a Bayesian framework will be adopted in which the Court has no ex-ante information concerning the characteristics of the $N$ individuals. The ex-ante probability of $i$ committing the crime, $p(i)$, will hence equal $\frac{1}{N}$. This is the (unconditional) probability a Court would assign to $i$ committing (or having committed) the crime, before the Court knows the evidence of the case. When receiving the evidence the Court updates its ex-ante probabilities based on conditional probabilities of observing the evidence. It will be assumed that for any evidence $e$ and any individual $i$ the Court can (in an approximate sense) answer the following question : if $i$ did commit the crime, what would be the probability then for the court to receive $e$. For any $e$, there are $N$ such conditional probabilities, and the idea of the present paper is to develop the other probabilities (e.g. of correct and wrongful conviction) from these conditional probabilities. Denote the conditional probability for individual $i$ by $\operatorname{prob}(e \mid i), i=1,2 \ldots N$.

The first variable to be determined from the conditional probabilities is the probability of any person $i$ 's guilt given the evidence $e$.

Note first that the probability of observing evidence $e$ can be expressed by conditional probabilities using the general formula that $\operatorname{prob}(X)=\operatorname{prob}(X \mid$ $Y) \operatorname{prob}(Y)+\operatorname{prob}(X \mid Z) \operatorname{prob}(Z)$, when $Y \cup Z=\Omega$ and $Y \cap Z=\emptyset$ :

$$
\operatorname{prob}(e)=\sum_{i=1}^{i=N} \operatorname{prob}(i) \operatorname{prob}(e \mid i)
$$

\footnotetext{
${ }^{5}$ If a person belongs to a group with an above-average propensity for crime, his or her ex-ante probability of guilt will, ceteris paribus, be correspondingly higher. The model can be generalized in this direction.
} 
Bayes' formula ${ }^{6}$ can then be used to derive the probability of $i$ 's guilt given the evidence $e, \operatorname{prob}(i \mid e)$ :

$$
\operatorname{prob}(i \mid e)=\frac{\operatorname{prob}(i \cap e)}{\operatorname{prob}(e)}=\frac{\operatorname{prob}(i) \operatorname{prob}(e \mid i)}{\sum_{j=1}^{j=N} \operatorname{prob}(j) \operatorname{prob}(e \mid j)}
$$

Since $\operatorname{prob}(i)=\operatorname{prob}(j)=\frac{1}{N}$, the first proposition can be stated:

Proposition 1: The probability of person $i$ 's guilt given the evidence $e$ can be expressed from the conditional probabilities as

$$
\frac{\operatorname{prob}(e \mid i)}{\sum_{j=1}^{j=N} \operatorname{prob}(e \mid j)}
$$

The proposition reflects the basic Bayesian logic, that the probability of $i^{\prime}$ s guilt given the evidence is the ratio of two probabilities: the probability of observing the evidence when $i$ committed the crime and the probability of observing the evidence at all. Both of these probabilities are joint, but due to the assumption of symmetry (all a priori probabilities of guilt equal $1 / N$ ), the a priori probabilities cancel out, and hence the ratio of the conditional probabilities determines the probability of guilt ${ }^{7}$.

Also, the proposition reflects in an approximate sense the way in which a defendant's probability of guilt is inferred in reality. In forming the probability of guilt of the defendant, the Court will compare how compatible the evidence is on one hand with the hypothesis that the defendant committed the crime and on the other hand with the hypothesis that someone other than the defendant committed the crime. Naturally, the proposition establishes an ideal benchmark that may not be fully descriptive of actual inference; real world decision making is unlikely to mimic Bayesian updating perfectly, one can e.g. imagine that very small probabilities are simply left out of consideration in reality.

Note finally that the prime suspect can naturally be defined as that person whose probability of guilt, as determined by the proposition, is the highest given the evidence before the Court. And that the weight of the evidence for each individual can be defined in terms of the probability of guilt which it establishes for that individual. These two concepts, the prime suspect and the weight of the evidence are sometimes taken as self-evident; in the present context, the former is easily defined while the latter is not needed as a concept.

\footnotetext{
${ }^{6} \operatorname{prob}(X \mid Y)=\frac{\operatorname{prob}(X \cap Y)}{\operatorname{prob}(Y)}=\frac{\operatorname{prob}(Y \mid X) \operatorname{prob}(X)}{\operatorname{prob}(Y)}$

${ }^{7}$ In a setting where ex ante probabilities of guilt differ between individuals, these probabilities would not cancel out but would remain in the expression.
} 
Denote by $e^{i}(p)$ the evidence ${ }^{8}$ that points to individual $i$ 's guilt with probability $p, i=1,2 \ldots N$. And denote by $e_{j}^{i}(p)$, the event that the evidence pointing to $i$ with probability $p$ occurs when $j$ committed the crime, $i, j=1,2 \ldots N$. The events $e_{i}^{i}(p)$ (for any $i$ ) concern the evidence of weight $p$ arising against the offender while the events $e_{j}^{i}(p)$ where $i \neq j$ concern the evidence arising against an innocent individual. The probability of these events will now be considered from the viewpoint of the Court.

The probability of one of the events $e_{i}^{i}(p)$ occuring $(i=1,2 \ldots N)$ is the probability that evidence of weight $p$ comes forth against the offender, sometimes referred to as $f_{g}(p)$ where $g$ refers to guilt. The events are mutually exclusive, hence

$$
f_{g}(p)=\frac{1}{N} \operatorname{prob}\left(e_{1}^{1}(p)\right)+\frac{1}{N} \operatorname{prob}\left(e_{2}^{2}(p)\right) \ldots+\frac{1}{N} \operatorname{prob}\left(e_{N}^{N}(p)\right)
$$

Since $\operatorname{prob}\left(e_{i}^{i}(p)\right)$ is the same for all $i$ in the present symmetric model, $f_{g}(p)$ can be written $\frac{1}{N} \sum_{i=1}^{i=N} \operatorname{prob}\left(e_{i}^{i}(p)\right)=\operatorname{prob}\left(e_{i}^{i}(p)\right) \cdot \operatorname{prob}\left(e_{i}^{i}(p)\right)$ derives from the conditional probabilities as follows: the evidence $e^{i}(p)$ that points to $i$ as the offender with probability $p$ is the evidence which fulfills $\frac{p \operatorname{prob}(e \mid i)}{\sum_{j=1}^{j=N} \operatorname{prob}(e \mid j)}=p$, in which all expressions are conditional probabilities, and the probability of that evidence occurring when $i$ committed the crime equals $\operatorname{prob}\left(e^{i}(p) \mid i\right)$, which is also a conditional probability.

Proposition 2: The probability of evidence of weight $p$ arising against the offender, $f_{g}(p)$, equals the conditional probability $\operatorname{prob}\left(e^{i}(p) \mid i\right)$ where $e^{i}(p)$ solves (for $e$ ): $\frac{p r o b(e \mid i)}{\sum_{j=1}^{j=N} \operatorname{prob}(e \mid j)}=p$.

The second concept to derive from the conditional probabilities is the probability of evidence of weight $p$ coming forth against someone other than the offender, $f_{i n}(p)$. Consider the probability that evidence of weight $p$ arises against $i$ when $j$ has committed the crime, $\operatorname{prob}\left(e_{j}^{i}(p)\right)$. To calculate this probability consider the following matrix:

$$
\begin{array}{lll}
e_{1}^{1}(p) & e_{1}^{2}(p) & e_{1}^{N}(p) \\
e_{2}^{1}(p) & \cdots & \\
\cdots & & \\
e_{N}^{1}(p) & & \\
& & e_{N}^{N}(p)
\end{array}
$$

In this matrix, $p$ is assumed to be greater than $\frac{1}{2}$; conviction will not occur when $p<\frac{1}{2}$, and restricting attention to $p>\frac{1}{2}$ implies that events in the matrix become mutually exclusive as the evidence cannot point to two people with probability greater than $\frac{1}{2}$.

\footnotetext{
${ }^{8}$ It can be assumed without loss of generality that two different constellations of evidence do not produce the exact same probability of guilt.
} 
The events in the diagonal represent evidence pointing to the offender with probability $p$. The probability of these events was calculated above. Off the diagonal, the evidence points with probability (greater than $\frac{1}{2}$ ) to the guilt of someone other than the offender. Hence, of interest is the sum of the probabilities of the events off the diagonal:

$$
\sum_{i=1}^{N} \sum_{j \neq i} \operatorname{prob}\left(e_{j}^{i}(p)\right)
$$

The probability of evidence of weight $p$ arising against $i$ when $j$ committed the crime equals the conditional probability $\operatorname{prob}\left(e^{i}(p) \mid j\right)$ where $e^{i}(p)$ solves (for $e): \frac{\operatorname{prob}(e \mid i)}{\sum_{j=1}^{j=N} \operatorname{prob}(e \mid j)}=p$. That is, when the Court attaches probability $p$ to $i$ having committed the crime, it is because the evidence is such that $\frac{\operatorname{prob}(e \mid i)}{\sum_{j=1}^{j=N} \operatorname{prob}(e \mid j)}=p$, and this evidence $e^{i}(p)$ occurs with probability $\operatorname{prob}\left(e^{i}(p) \mid j\right)$ when $j$ committed the crime.

The probability of observing evidence of weight $p$ against $i$ given that $j$ committed the crime, $\operatorname{prob}\left(e^{i}(p) \mid j\right)$, is by symmetry of the model the same for all pairs $(i, j)$ where $j \neq i$, and we can hence denote it by a common expression $f_{i j}(p)$. The probability that this event occurs is then $\frac{1}{N} f_{i j}(p)$ where $\frac{1}{N}$ is the probabiliy that $j$ commits the crime. Hence, $\sum_{j \neq i} \operatorname{prob}\left(e_{j}^{i}(p)\right)=\sum_{j \neq i} \frac{1}{N} f_{i j}(p)=$ $\frac{N-1}{N} f_{i j}(p)$, and $\sum_{i=1}^{N} \sum_{j \neq i} \operatorname{prob}\left(e_{j}^{i}(p)\right)=(N-1) f_{i j}(p)$.

Proposition 3: The probability $f_{i n}(p)$ of someone other than the offender being suspected with a probability of guilt equal to $p$, where $p>\frac{1}{2}$, equals $(N-1) f_{i j}(p)$ where $f_{i j}(p)$ is the conditional probability that evidence of weight $p$ will come forth against $i$ given that $j$ committed the crime.

Note that since $f_{i j}(p)$ has been derived from the basic conditional probabilities, so has the probability of wrongful conviction.

It may be thought that $(N-1) f_{i j}(p)$ increases with $N$ and cannot therefore be a probability, but when $N$ increases, $f_{i j}(p)$ decreases correspondingly, since the probability for each person to be wrongly convicted of a given crime falls with the size of the population.

Proposition 2 and 3 derive the probabilities $f_{g}(p)$ and $f_{i n}(p)$ from basic conditional probabilities. The analysis now turns to the probability of correct and wrongful conviction derived as a function of the standard of proof $q$, which is the treshold probability of guilt beyond which the Court convicts. Note that $f_{g}(p)$ and $f_{i n}(p)$ are well-defined when $p>\frac{1}{2}$, and that it is natural to restrict attention to $q>\frac{1}{2}$ for criminal trials. In the following it will be assumed for convenience that $p$ varies continuously such that total probabilities of conviction can be expressed by integrals. 
A defendant is convicted when $p>q$, hence:

Proposition 4: The probability that the offender is convicted equals $\int_{q}^{1} f_{g}(p) d p$

Naturally, it follows that the probability that the offender is not convicted, from which victims may suffer an unfairness 'cost' equals $1-\int_{q}^{1} f_{g}(p) d p$.

From the probability of convicting the offender the expected sanction from committing the crime can be derived, central of course to the deterrent effect.

Proposition 5: If the sanction is $s$, the expected sanction equals $s \int_{q}^{1} f_{g}(p) d p^{9}$.

It may be argued that deterrence is affected not only by the expected sanction but also by the probability of unfair conviction. However, in the present model, individuals do not risk conviction of a crime they do not commit, since the existence of a crime is not in question, and therefore an individual should not consider this risk when abstaining from a crime. And he or she may be wrongfully convicted of another's crime whether or not he or she commits a crime. Hence, the risk of wrongful conviction can be assumed not to affect the incentive for crime (for a further discussion, see Lando (2004)).

The risk of wrongful conviction follows in an equally simple way from the $f_{i n}(p)$ function:

Proposition 6: The risk that someone is wrongfully convicted equals $\int_{q}^{1} f_{\text {in }}(p) d p$

From proposition 4 and 6 follows the probability of conviction on a given day. Since a conviction is either correct or wrongful, the probability of a conviction on a given day is the sum of the probability of correct and of wrongful conviction.

Proposition 7: The probability of conviction on a given day, from which society's incarceration costs can be derived, equals $\int_{q}^{1} f_{g}(p) d p+\int_{q}^{1} f_{i n}(p) d p$

\section{Summary}

Two sets of questions have been analysed. The first concerns how a Court should infer the probability of guilt from given evidence before it. The second concerns how the standard of proof affects the probability of correct and wrongful conviction, the expected sanction and the expected incarceration costs,

\footnotetext{
${ }^{9}$ Note that one does not risk conviction of a cirme not committed when the existence of a crime is not in question, and that the risk of wrongful conviction therefore does not affect the incentive for crime. On this point, see Lando (2004).
} 
where all possible evidence that might arise in the wake of a crime should be taken into account. It is well-known from the law and economics literature (see e.g. Miceli (1990) and (1991)) that both sets of questions can be answered from two probability distributions: the probability of observing any given evidence against the offender and the probability of observing it against someone other than the offender. This article has derived these probability distributions from the conditional probabilities (one for each set of evidence and for each pair of individuals $(i, j)$ ) of observing the evidence against $i$ when $j$ (who may be identical to individual $i$ ) committed the crime.

\section{References}

[1] Becker, Gary: 'Crime and Punishment: An Economic Approach', Journal of Political Economy; 1968, 76 (2), pp 169-217.

[2] Lando, Henrik 'Does Wrongful Conviction Lower Deterrence', SSRN: http://papers.ssrn.com/sol3/papers.cfm?abstract_id=603962, 2004. Forthcoming in Journal of Legal Studies 2006.

[3] Lando, Henrik: Prevention of Crime and the Optimal Standard of Proof in Criminal Law http://papers.ssrn.com/sol3/papers.cfm?abstract_id=238334, 2003.

[4] Miceli, Thomas J: 'Optimal Criminal Procedure: Fairness and Deterrence', International Review of Law and Economics; 11(1), May 1991, pp 3-10.

[5] Miceli, Thomas: 'Optimal Prosecution of Defendants Whose Guilt is Uncertain', Journal of Law, Economics and Organization; 6(1), Spring 1990, pp 189-202.

[6] Polinsky, Mitchell and Shavell, Steven: 'The Economic Theory of Public Enforcement of Law', Journal of Economic Literature; 38, 2000 pp. 45-76. 